diseases and in strengthening national health services. During the year about 570,000 persons in Morocco and Tunisia were treated for trachoma, a high percentage of cures being obtained. Measures were taken to protect about two-fifths of the estimated population of South-East Asia against malaria, and epidemic malaria is no longer prevalent in about half the island territories of the Caribbean; but it has become a matter of urgency to intensify the effects to eradicate malaria in these regions before the anopheline vectors develop too great a resistance to the insecticides at present used for their control. In Indonesia the mass campaign against yaws has brought the disease under control in about thirty areas, while in Thailand $7 \cdot 5$ million people have been surveyed and about 750,000 treated for the same disease. As examples of assist. ance given to improve housing conditions, the report cites the establishment in India of a research centre to study the socio-economic and technological aspects of housing development in a dry tropical climate and of another in Indonesia to study these factors in a humid tropical climate. More than a thousand Civil servants of various grades received training during the year, and in Jordan, on the recom. mendation of an expert on Civil Service reform, a Civil Service Department and a Civil Service Commission were set up; technical consultants in Bolivia helped to draft legislation establishing a permanent Civil Service, and the postal services in Iran, Lebanon and Uruguay have been considerably improved as a result of international advice and assistance.

Although most of the experts supplied in 1955 were recruited from Europe and North America, they were drawn from sixty-nine countries and territories, and workers in receipt of fellowships studied in ninety-four. During the year, 2,431 fellowships were granted, as compared with 1,524 in 1954 and 1,195 in 1953, and there has been a growing trend towards the establishment of training institutes within countries which are receiving technical assistance. Special attention has been paid to co-ordination of the technical assistance provided under the expanded programmes and under bilateral aid programmes, while the general financial stability of the Expanded Programme considerably improved during the latter part of the year.

\section{INDIA'S CONTRIBUTION TO THE HISTORY OF MEDICINE}

$T$ HE publication, in June, of the first number of the Indian Journal of the History of Medicine* is in itself an event of historic importance. Much of the credit for this noteworthy step is due to Prof. D. V. Subba Reddy, who founded the Indian Association of the History of Medicine nine years ago, and became its first secretary. Prof. Reddy is editor of the new Journal, which is to be the organ of the Association and will be published twice a year, and he will also shortly vacate his chair of physiology in the University of Madras in order to assume the duties of a chair of history of medicine, the first of its kind in India.

* Indian Journal of the History of Medicine, 1, No. 1 (June 1956). Pp. iv +69. (Madras: Indian Association of the History of Medicine,
1956.) Rs, 8 per year (two issues) or foreign currency equivalent to Rs. 12 .
By the creation of a new chair and a Journal, India has recognized, most opportunely, the importance of a historical perspective in medicine. The Medical Education Conference, set up by the Government of India, which met in Delhi in November 1055, acted wisely in recommending that history of medicine should be included in the medical curriculum. This decision was made for several reasons. Not only has the subject a special cultural and humanistic value, but also, as the report of the Conference states, "after studying the history of medicine, the future medical practitioner will be better equipped for his profession under conditions prevailing in this country. Our people think and talk about their illnesses in terms of ideas and expressions based largely on our ancient systems of medicine. How can a physician understand fully what his patient describes as his symptoms unless he has an acquaintance with these ideas and ways of giving expression to them ?"

This very appropriate argument in favour of the study of medical history may not apply in every country, but it is certainly valid for India. Events have moved rapidly, and already the report has borne fruit. Dr. Reddy is to be warmly congratulated on the high standard which has been attained in the first number of his Journal. It is a veritable mine of information on the early medicine of India and the East. The opening paper, which was originally an address to the Association, is a scholarly contribution by Prof. J. Filliozat (French College at Pondichery) on Ayurveda and foreign contacts, showing the links between Indian medicine and Greek medicine; Prof. P. Kitumbiah (Christian Medical College, Vellore) contributes a paper on the concept of heart and blood. vessels in ancient Hindu medicine; and Prof. M. V. Sastry (Madras) writes on training for medical practice in ancient India. Prof. Reddy himself supplies an article on Buddha's discourses on medicaments, treatment and nursing; other authors deal with nursing under ancient Indian systems, with Arabian medicine and with Rhazes' magnum opus, "Al-Hawi, or Continens". The Journal, which is well produced and clearly printed, will be published twice a year. It deserves every encouragement.

This recognition by India of the importance of history in medicine is a welcome sign of progress. Many other countries have become aware of their medical heritage. Throughout Europe, nearly every university has its chair of history of medicine and there are many institutes which serve as centres of knowledge. In the United States and in South America, especially in Brazil and Venezuela, close attention is given to the history of medicine.

Towards this widespread awareness of the value of history as a cultural and ethical basis of medical education, Britain alone shows an attitude of almost complete indifference. In London, the Wellcome Historical Medical Library and Museum continue to stimulate and keep alive an interest in the past, as also do the various societies of history of medicine, in England, Scotland and Ireland. The tale of neglect is truly surprising. Nevertheless, a more cheerful attitude is foreshadowed by the recent news that a British journal-the only one of its kind-entitled Medical History, will eommence publication next January under the editorship of the well-known medical historian, Mr. W. J. Bishop, and will appear quartierly.

One of the strongest arguments in favour of medical history is that it directs attention to the ever-present need for an application of the principles originally 
embodied in the Oath of Hippocrates. Recognizing this need, the universities and medical schools of Europe, since the days of the School of Salerno, have demanded of their graduands some form of promise based upon the Hippocratic Oath, and this practice is now followed in many parts of the world. In Britain, although each of the four Scottish universities follows the age-long tradition, only two or three of the many English universities accord any official recognition to the great charter of medical conduct which has come down to us through the centuries from the time of Hippocrates. Surely a knowledge of such ethical principles, if not also of the pioneers who codified and practised them, should be regarded as a feature essential to every medical curriculum ?

Accordingly, while we in Britain may well congratulate our Indian colleagues upon their foresight in appreciating the value of the historical aspect of medicine, we may at the same time feel ashamed of our own failure to do so. There is still much to be accomplished in the reform of medical education, and, if medicine is to remain one of the learned professions, more stress must surely be laid upon ethics and humanism, which only reveal their importance during a study of the history of medicine. For Hippocrates, medicine was ever "The Art". Only as an art can it preserve its fine tradition. All honour, therefore, to India for reminding us that only by looking backward can we recapture the true spirit of medicine. In this way alone can we effectively face the future.

Douglas GUThrif

\section{THE MYXOPHYCEAE AND CHLOROPHYCEAE OF NEW ZEALAND}

COME comparatively recent American marine Floras have set a satisfactory standard against which a reader is prone to measure new works of a similar kind. Of prime scientific importance would seem to be the provision of concise but complete diagnoses of the various taxa, namely, orders, families, genera and species, including details of both vegetative and reproductive characters. Good keys based on easily discernible characters (and, so far as possible, macroscopic features of the vegetative parts of the thallus) should lead to the relevant descriptions. Good illustrations should reinforce the statements about the salient characters of the genus, both vegetative and reproductive. In some genera this would need to be supplemented by illustration of one particular character for all the species, where it is of prime taxonomic importance. Lastly, in a group of plants in which terminology is notoriously imprecise, a glossary is necessary. From the practical point of view, a Flora should be of manageable size and provided with firm covers.

The first part of the "Marine Algae of New Zealand", by Prof. V. J. Chapman, that dealing with the Myxophyceas and Chlorophyceae (J.Linn. Soc. Lond., 55, No. 360, 333-501 ; July 1956; 42s.), falls short of these standards. Since the work is published in a journal, the author may not have had an orthodox Flora as his aim; but if not, what was it, as the paper has the form of such but without much of the substance? The species descriptions are brief and would probably prove difficult, therefore, for beginners. One of the shortest is that for Ostreobium reineckei Born., namely: "Filaments intricately spreading, the ends of the branches consistently free". Even the newly described species are not given very lengthy treatment. Throughout the work, mention of the reproductive organs is very meagre, and illus. trations of these parts of the thalli are conspicuous by their absence. References to other works are given under the binomial system; but it is not clear what rule has governed the choice of citations when it is not the original description. Keys at the beginning of each of the two sections lead to families and not orders and yet keys are given again under each order to the families of that order, so that there is considerable duplication. The Wittrockiellacea is an exception, as it occurs under the order heading only. No glossary is provided, and sometimes the choice of terms is not good; for example, "plant body". Again, in Table 1 "exposure" is used to mean something different from the same word on the opposite page (p. 339), where it is the equivalent of emergence (cf. p. 335). "Filamentous" is also used in more than one sense, in some instances to signify the construction of the thallus and in others to describe its filiform shape.

An editor's note explains that the twenty-seven plates are reproduced as faithfully as the quality of the illustrations provided allowed, and this would appear to be the case. Legends for these plates would have added to their value, especially since notes on the illustrations are not always legible. Some of the one hundred and fifty-three text-figures, which are the work of the author and his associates, lack information about magnification and also precision as regards other details. Hence they are not always as informative as could be wished. In spite of its certain lack of perfection, the work is a considerable advance on Laing's list of 1926. In the latter, there are only seven species of Myxophyceae and forty-six Chlorophyceae, whereas in the work under review there are fifty-four species of Myxophyceae and two hundred and five species of Chlorophycea. This indicates the amount of work which has gone into the preparation of this Flora in the comparatively short amount of time since Prof. Chapman went to New Zealand. Moreover, the paper was read at the Linnean Society more than two years ago.

Although the number of species of Myxophycea listed is greatly in excess of that of Laing's list, the author points out that it is likely that more exist on the shores of New Zealand, and this is doubtless the case. The species known already are ones with a wide distribution in the world and there is only one doubtfully endemic species, Tolypothrix irregularis. In contrast, out of two hundred and five species of Chlorophycea listed, ninety-two (47 per cent) are endemic. Some of these have a restricted distribution so far as is known at present. 'The new genus, Gemina, is characteristic of southern cold waters, and Bryopsis is a conspicuous genus in South Island, from which district have come species not previously described. The author goes so far as to suggest that the South Pacific is either the home of the genus or that active evolution is taking place around the shores of New Zealand. The genera Lobata (Ulvaceae) and Rama (Cladophoraceae) as well as Gemina (Ulvacear), all described earlier by Chapman, are included in the Flora, as well as many new species.

In the Myxophyceae, the author has accepted Drouet and Daily's (1948) views on the classification 